\title{
Adaptation of farming practices by the smallholder farmers in response to climate change
}

\author{
Billah, M. M., Sarker, M. A., Miah, M. A. M. and Kabir, K. H. ${ }^{*}$ \\ Department of Agricultural Extension Education, Bangladesh Agricultural University, Mymensingh-2202, \\ Bangladesh.
}

Received 10 August 2015; Accepted 21 January 2015

\begin{abstract}
The study was conducted to determine the extent of adaptation of farming practices by smallholder farmers in response to climate change in coastal regions of Bangladesh. The data were collected from $\mathbf{8 0}$ randomly selected smallholder farmers with the objectives to identify the adaptation of farming practices, to determine the factors those influence adaptation of farming practices and to find out the constraints faced by the farmers in adapting farming practices. The findings of the study revealed that majority (75\%) of the smallholder farmers made low to medium adaptation of farming practices in response to climate change. Correlation analysis indicated that among the selected socio- economic characteristics, respondent's education, annual family income, communication exposure, agricultural training and perception of climate change showed positive and significant relationship with their adaptation of farming practices. Step-wise multiple regression analysis explored that amongst six, four independent variables finally entered into the model and contribution of these factors (education, perception, communication exposure and training) accounted for $88 \%$ of the total variation in the extent of adaptation of farming practices. It was found that majority $(76 \%)$ of the smallholder farmers had faced high to medium constraints in adapting farm practices in response to climate change.
\end{abstract}

Key words: Adaptation, farming practices, smallholder farmers and climate change.

\section{INTRODUCTION}

Climate change and variability is commonly associated with food insecurity in many parts of the world. The relationship between climate change/variability and crop failure is not a new phenomenon, but in areas where infrastructure is limited, poor people are often vulnerable climate hazards (Ziervogel et al., 2008). The challenge climate change poses to the world's $\mathbf{5 0 0}$ million smallholder farms cannot be overlooked. Smallholder farmers provide up to $80 \%$ of food in sub-Saharan Africa and parts of Asia, manage vast areas of land and make up the largest share of the developing world's undernourished people (ASAP, 2012). The Fourth Assessment Report of the Intergovernmental Panel on Climate Change (IPCC) predicts that climate change is likely to have a significant effect on agricultural production in many African countries. Projected reductions in yield in some African countries could be as much as $50 \%$ by 2020 , and net crop revenues could fall by $90 \%$ by 2100 (Boko et al., 2007). This amounts to a 
serious threat to food security and to the achievement of major developmental goals. The agricultural sector is a major source of livelihood in Southeast Asia. With agriculture's dependence on optimal temperature and water availability, climate change has been and will continue to be a critical factor affecting the productivity of crop. Major cereal crops such as rice and maize have experienced declining production potential due to heat and water stress (ADB, 2009). The IPCC states with high confidence that smallholder and subsistence farmers in developing countries are among those who will suffer the most from climate change impacts.

Bangladesh is an agro-based country and agriculture is the backbone of national economy. More than $80 \%$ of total population is directly or indirectly involved with agriculture. Agriculture contributes $19.29 \%$ to its GDP. More than $75 \%$ of foreign exchange is earned from agriculture based commodities (BBS, 2012). On the other hand, Bangladesh is extremely vulnerable to the impact of climate change, in part because it is a low-lying and very flat country, subject to riverine flooding and vulnerable to sea level rise. The confluence of the three great rivers, the Ganges, the Brahmaputra and the Meghna, makes the country a great deltaic plain. The extensive floodplains are the main physiographic features of the country. Both riverine flooding and sea level rise can result in inundation of crops; sea water, in particular, can result in salinization, causing permanent loss of currently productive agricultural land (Thomas et al., 2012). Climate change in Bangladesh is an especially serious concern since agriculture is such an important sector. It contributes roughly $20 \%$ to GDP, with crops representing $11.2 \%$, livestock $2.7 \%$, fisheries $4.5 \%$, and forestry 1.8\% (Bangladesh Economic Review, 2010). Furthermore, the sector provides employment and income to some of the poorest and most vulnerable members of society. Between 2000 and 2003, agriculture provided work to about $52 \%$ of the labor force (BBS Labor Force Survey 2011-2012).

Asian Development Bank (ADB) and International Food Policy Research Institute (IFPRI) (2009) studied the impact of climate change on agriculture in the countries of Asia and the Pacific, concluding that "a combination of indicator values representing exposure (change in temperature and precipitation), sensitivity (share of labor in agriculture), and adaptive capacity (poverty) identifies Afghanistan, Bangladesh, Cambodia, India, Lao PDR, Myanmar, and Nepal as the country's most vulnerable to climate change. "We cannot imagine a single moment without the contribution of agriculture but it is being destroyed by various natural and man-made events. Climate change is one of those events which are directly responsible for hampering this sector. Climate is commonly defined as the average weather for a long period of time for the given region. Climate change is a statistically significant change in the measurement of either the mean state or variability of the climate for a place or region over an extended period of time due to natural variability or as a result of human interventions (Prevention consortium, 2007). Climate change is becoming the greatest threat in the history of humanity. Bangladesh is one of those countries that have been fighting against this global threat for the last few decades. According to a World Bank (WB) report, the losses associated with environmental degradation are estimated at more than $4.3 \%$ of Bangladesh's GDP and result in reduced the capacity of government's poverty alleviation programs (World Bank, 2006).

Bangladesh is a disaster-prone country and due to these unwanted events, the country experiences disasters of one kind or another (such as tropical cyclones, storm surges, coastal erosion, salinity intrusion, floods, and droughts) almost every year causing heavy loss of life and resources and jeopardizing the development activities (NAPA, 2005). The country is already beset with many problems like high population density, shortage of land to accommodate the people, food security, human health and so forth. The above mentioned types of disasters make the problems all the more complicated. In the foreseeable future, Bangladesh is likely to be one of the most vulnerable countries of the world in the event of climate change. Here smallholder farmers are very vulnerable to current and future climate risk (that is, drought, flood, cyclone etc.). This is evidence by the high loss of property and life in recent climate-related hazards around the country. Without the application of productivity improvements and adaptations, the agriculture sector in Bangladesh has to suffer. Significant losses, are threatening food security in that region (ADB, 2009).

Adaptation to climate change refers to adjustment in natural or human system in response to actual or expected climatic stimuli or their effects, which moderates harm or exploits beneficial opportunity (IPCC, 2007). The main goal of climate change adaptation is to reduce vulnerability and build resilience to the impacts brought by climate change (Brooks and Adger, 2005). Moreover, farmers have a long history of responding to climate variability. Traditional and newly introduce adaption practices can help farmers to cope with both current climate variability and future climate change (Bilow, 2010). Several adaptive practices are regularly considered by the smallholder farmers in the local agriculture but the relative success to overcome climatic condition and temporal variations of climatic elements gradually making coastal people vulnerable. Furthermore, adaptation generally takes place at the micro- and macrolevels: Farmers introduce practices at the local level, and the main factors influencing their diffusion are seasonal climatic variations, the agricultural production system, and other socioeconomic factors; the government, NGOs, or private companies introduce practices nationally, and long-term changes in climatic, market, and other conditions influence their establishment (Nhemachena and Hassan 2007). In this situation, the adaptive capacities of the people need to be gradually increased to understand the probabilistic climate vulnerabilities and its consequences over the agriculture and agriculturally based livelihoods 
(CEGIS, 2005).

Several comprehensive studies of farmers' adaptation to climate change focus on a few study sites or regions in one or two countries (Osbahr et al., 2008; Osman-Elasha et al., 2006; Paavola, 2004; Thomas et al., 2007). Mbilinyi et al. (2005), for example, discuss indigenous knowledge about rainwater harvesting; Halsnaes and Traerup (2009) assess the economic benefits of mosquito nets, road infrastructure, and rice production; and Siedenburg (2008) analyzes the implications of local knowledge for the adoption of agroforestry practices. Adger et al. (2007) provide a broad overview of adaptation practices concerning different sectors of the economy in Africa, Asia, Oceania, the Americas, and Europe. Boko et al. (2007) give general examples of adaptation options in Africa that enhance citizen's social and economic resilience. Finally, Smit and Skinner (2002) developed a typology for classifying and characterizing agricultural adaptation options in detail, focusing on Canada.

However, the literature they reviewed contains no specific study to identify the adaptation practices and to determine the factors those influence adaptation of farming practices by small-scale farmers in Bangladesh.

Though several government programs have sought to address climate risks in Bangladesh, new ways and methods need to be developed that better inform farmers and help them to identify alternative, technically viable options for farm adaptation practices to mitigate the consequences of climate change (Toufiq, 2002). Thus, in this situation it is necessary to know the extent of adaptation of farm practices and also explore some potential factors that are influencing the adaptation of farming practices in response to climate change and that is why this study was drawn over this area.

\section{METHODOLOGY}

\section{Locale of research}

The study was conducted in two unions namely Padma pukur and Kashimari of Shyamnagar upazila under Satkhira district. Most of the farmers in this area are smallholders whose livelihood depends on various farming activities. Their farming activities are being changed and affected due to climate change. The area is mainly affected by salinity, sea level-rise, flood, cyclone etc. About $49.38 \%$ of the total farmers are smallholder farmers in Shyamnagar upazila and around 200 small farmers live in each village (BBS, 2006). The total target population was 400 , out of which $20 \%$ population were selected from two villages as sample. Hence, the sample size was 80 . Data were collected during April 2013 using structured questionnaire. Two FGDs and two KII were conducted in order to get in depth information on adaptation practices (Figure 1).

\section{Data collection}

The total target population was 400 , out of which $20 \%$ population were selected from two villages as sample. Hence, the sample size was 80. Data were collected during April 2013 using structured questionnaire. Two FGDs and two KII were conducted in order to get in depth information on adaptation practices. In order to collect qualitative data, two group discussion sessions were arranged in the study areas. Each group contained 10 participants. The qualitative data helped the researcher to design interview schedule for the study. A personal interview was conducted with the 80 respondents through the interview schedule in April 2013.

The extent of adaptation of farming practices in response to climate change was the dependent variable of the study. The eight selected characteristics of the smallholder farmers namely age, level of education, household assets, annual family income, credit received, communication exposure, training received and perception of climate change were the independent variables of this study. The variable was measured on the basis of different aspects of adaptation. The adaptation score was computed on the basis of the respondents' adaptation on 15 aspects. A-four point rating scale was developed to measure the extent of adaptation of the farmers namely frequently, occasionally, rarely and not at all score assigned for each of these responses were 3,2,1 and 0 respectively. Thus, score of a smallholder farmer in 15 items could range from 0 to 45 .

\section{Data analysis}

The collected data were coded, categorized, tabulated and analyzed scientifically. The local units were converted into standard units. The qualitative data were transferred into quantitative data by appropriate scoring techniques. The SPSS computer program was used for analyzing the data. Various descriptive statistical measures such as range, frequency, number, percentage, mean, standard deviation (SD), coefficient of variation (CV) and rank order were used for categorization and describing the variables. Pearson's product moment correlation coefficient $(r)$ was utilized both for data evaluation and hypotheses testing. To identify the factors influencing adaptation of farming practices a step-wise multiple regression analysis was conducted.

\section{RESULTS AND DISCUSSION}

\section{Socio-demographic characteristics of the smallholder farmers}

The findings of the study indicate that the highest portion of the respondents $(42.5 \%)$ were young aged while majority $(41.2 \%)$ of the respondents had primary education. The majority (95\%) of the smallholder farmers had low to medium household assets and highest portion $(85.0 \%)$ of the respondents had low annual income while most $(63.8 \%)$ of respondents received low amount of credit. The study also reveals that majority $(57.5 \%)$ of the farmers' maintained moderate type of communication exposure for adapting farm practices. In terms of training exposure, the findings indicate that majority $(60.0 \%)$ of respondents received short duration training and the highest portion of the respondents $(55.0 \%)$ had observed moderate perception of climate change (Table 1).

\section{Extent of adaptation of farming practices}

The extent of adaptation of farming practices in response to climate change is the depended variable of this study. The adaptation score of the respondents ranged from 11 to 39 against the possible range of 0 to 45 


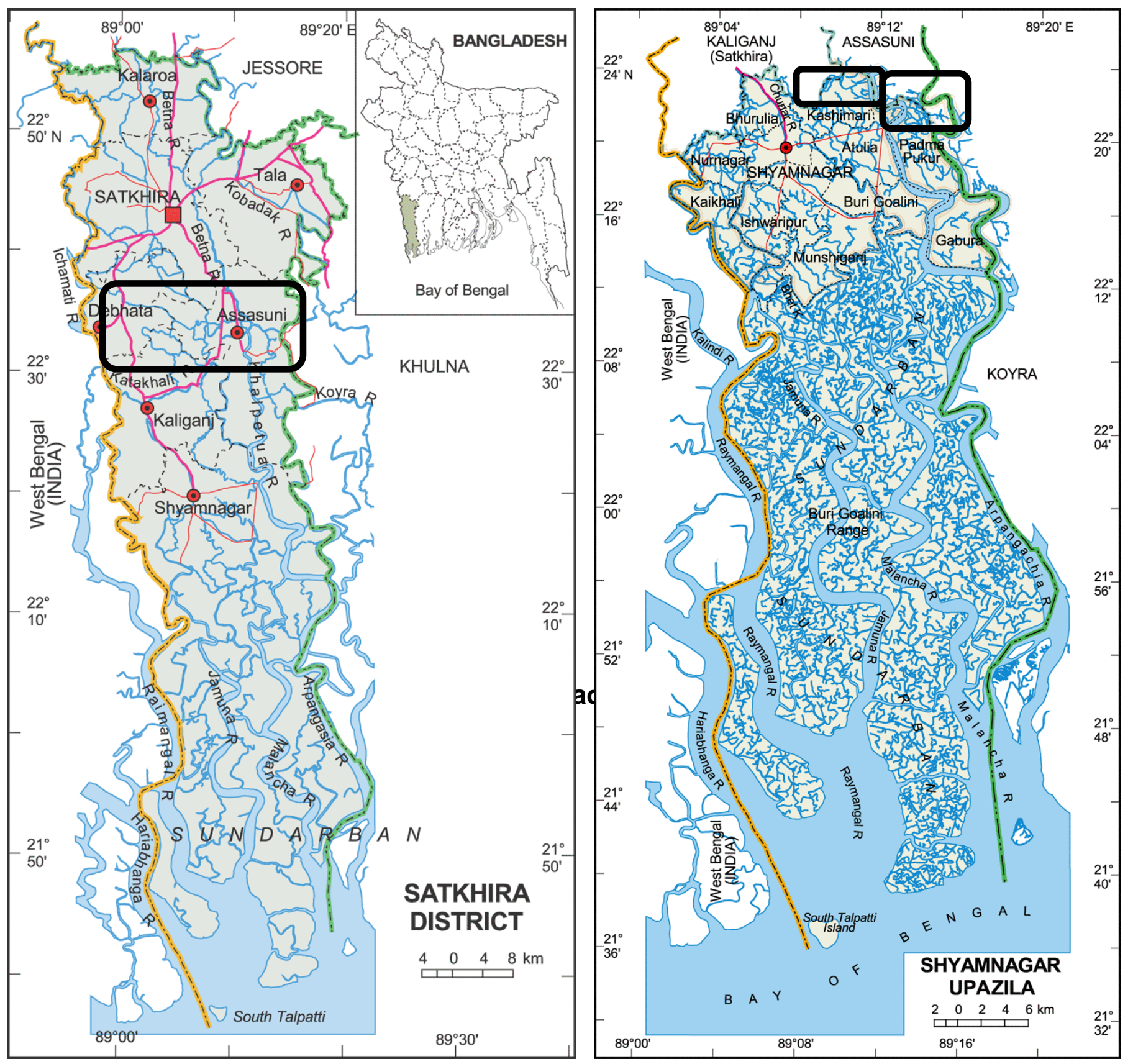

Figure 1. Map of Satkhira District of Bangladehs showing the study area of the Shyamnagar Upazila.

with an average of 25.74 and standard deviation 7.84. Findings indicate that majority of the respondents (53.8\%) had medium farm adaptation compared to $25.0 \%$ had high adaptation and $21.2 \%$ had low adaptation of farming practices in response to climate change and it is shown in Table 2.

It is evident from the figure that amongst the fifteen long-term practices the homestead gardening (92\%) belongs to the first position followed by moved to non farm activities (83\%), crop diversification (62\%), integrated farming system (60\%), find off farm jobs (57\%) etc (Figure 2).

\section{Relationship between dependent and independent variables}

Table 3 shows that age of the smallholder farmers were negatively significant while household assets and credit received had no significant relationship with the farmers' 
Table 1. Salient features of the selected characteristics of the farmers.

\begin{tabular}{|c|c|c|}
\hline \multirow{2}{*}{ Socio-economic variable } & \multicolumn{2}{|c|}{ Farmers $(\mathrm{n}=80)$} \\
\hline & Mean (Std. deviation) & $(\%)$ \\
\hline \multicolumn{3}{|l|}{ Personal data } \\
\hline Age (years) & $42.98(11.94)$ & - \\
\hline Young (up to 35) & - & 42.5 \\
\hline Middle aged (36-55) & - & 40.0 \\
\hline Old aged (above 55) & - & 17.5 \\
\hline Level of education & 5.7 (3.95) & - \\
\hline Illiterate $(0)$ & - & 11.2 \\
\hline Primary education (1-5) & - & 41.2 \\
\hline Secondary education (6-10) & - & 35.0 \\
\hline Higher education (above 10) & - & 12.6 \\
\hline Household assets (thousand) & $11.29(10.43)$ & - \\
\hline Low (up to 100 ) & - & 65.0 \\
\hline Medium (101-200) & - & 30.0 \\
\hline High (above 200) & - & 5.0 \\
\hline \multicolumn{3}{|l|}{ Farm data } \\
\hline Credit received (In thousand taka) & $24.13(20.78)$ & - \\
\hline No credit (0) & - & 13.4 \\
\hline Low credit (up to 35) & - & 63.8 \\
\hline Medium credit (36-70) & - & 20.0 \\
\hline High credit (above 70) & - & 2.8 \\
\hline Annual family income (thousand taka) & $48.26(20.18)$ & - \\
\hline Low income (up to 60 ) & - & 85.0 \\
\hline Medium income (61-100) & - & 11.2 \\
\hline High (above 100) & - & 3.8 \\
\hline Communication exposure (scale score) & $21.40(6.77)$ & - \\
\hline Poor exposure (up to 14) & - & 21.2 \\
\hline Medium exposure (15-28) & - & 57.6 \\
\hline High exposure (above 28) & - & 21.2 \\
\hline Agricultural training received (scale score) & $3.54(3.24)$ & - \\
\hline No training ( 0 days) & - & 32.5 \\
\hline Short training (1-7days) & - & 60.0 \\
\hline Medium training (8-14days) & - & 6.2 \\
\hline Long training (above 14days) & - & 1.3 \\
\hline Perception of climate change (scale score) & $17.95(5.47)$ & - \\
\hline Low perception (up to 10 ) & - & 12.5 \\
\hline Medium perception (11-20) & - & 55.0 \\
\hline High perception (above 20) & - & 32.5 \\
\hline
\end{tabular}

Table 2. Distribution of the farmers according to the extent of adaptation.

\begin{tabular}{lcccc}
\hline Categories & No. & Percent & Mean & SD \\
\hline Low adaptation (up to15) & 17 & 21.2 & & \\
Medium adaptation (16-30) & 43 & 53.8 & & \\
High adaptation (above 30) & 20 & 25.0 & & 7.84 \\
Total & $\mathbf{8 0}$ & $\mathbf{1 0 0 . 0}$ & & \\
\hline
\end{tabular}

Source: Author's Survey, 2013. 


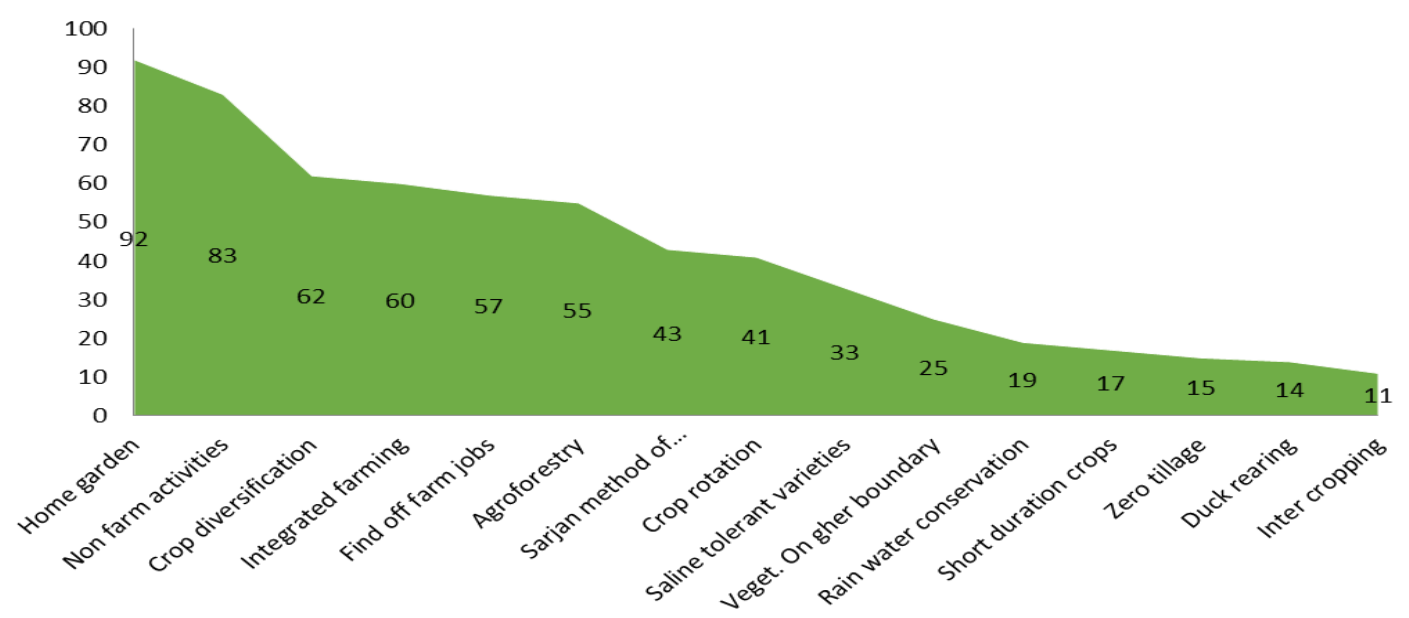

Figure 2. Adaptation practices followed by the smallholder farmers.

Table 3. Correlation analysis influencing adaptation practices of smallholder farmers.

\begin{tabular}{lc}
\hline Variables & Correlation co-efficient $(\mathbf{r})$ \\
\hline Age & $-0.419^{\star *}$ \\
Education & $0.898^{\star *}$ \\
Household assets & 0.058 \\
Income & $0.691^{* \star}$ \\
Credit & 0.113 \\
Training & $0.832^{* \star}$ \\
Communication exposure & $0.834^{* \star}$ \\
Perception & $0.881^{* \star}$ \\
\hline${ }^{* *}=$ Significant at $1 \%(0.01)$ level with 78 degree of freedom.
\end{tabular}

adaptation practices. On the other hand, level of education, annual family income, communication exposure, training and perception of climate change were positively correlated with the farmers' adaptation practices in response to climate change.

\section{Factors influencing adaptation of farming practices}

A step-wise multiple regression analysis had been applied to identify the significant explanatory variables that have effect on adaptation of farming practices. The results of the multiple regression analysis show that among the explanatory variables, four variables namely level of education, perception on climate change, communication exposure and training finally entered in the model and contribution together of these variables contribute to $88.2 \%$ of the total variance in respect to the effect on adaptation of farming practices (Table 4).

However, education solely contributes highest (80.4\%) to explain the adaptation of farming practices of the farmers in response to climate change. It may be assumed from the result of step-wise multiple regression analysis that farmers with more level of education have more rate of adaptation of climate smart farming practices. Farmers' perception on climate change, communication exposure to different extension media and more participation in training makes them potential and participatory in different adaptation practices in response to climate change.

\section{Constraints faced by the farmers in adapting farming practices}

The results show that the highest portion of the respondents $(38.8 \%)$ had faced medium constraints in adapting their farming practices, while $37.5 \%$ of the respondents had faced high constraints and only

$23.8 \%$ had faced low constraints. This means that the large portion $(76.2 \%)$ of the farmers had faced medium to high constraints and they were in the categories of middle to old aged and for clear understanding a bubble chart is given (Figure 3 ). It is a general assumption that the middle 
Table 4. Factors influencing adaptation of farming practices in response to climate change.

\begin{tabular}{|c|c|c|c|c|c|c|c|}
\hline Model & Combination of independent variables & $\begin{array}{l}\text { Co-efficient of } \\
\text { determination }\end{array}$ & $\begin{array}{l}\text { Adjusted } \\
\mathbf{R}^{2}\end{array}$ & $\begin{array}{l}\% \text { of increase in } \\
\text { Adjusted } \mathrm{R}^{2}\end{array}$ & F-value & t-value & $\begin{array}{l}\text { Sig. } \\
\text { level }\end{array}$ \\
\hline 1 & Constant + Education & 0.807 & .804 & 80.4 & $325.39^{* *}$ & 3.12 & .01 \\
\hline 2 & Constant + Education + Perception & 0.864 & .860 & 5.6 & $244.35^{\star *}$ & 3.18 & .00 \\
\hline 3 & Constant + Education + Perception +Communication & 0.878 & .873 & 1.3 & $181.76^{* *}$ & 2.80 & .00 \\
\hline 4 & $\begin{array}{l}\text { Constant }+ \text { Education } \\
\text { Communication }+ \text { Training }\end{array}$ & 0.888 & .882 & 0.9 & $147.93^{\star *}$ & 2.33 & .03 \\
\hline
\end{tabular}

${ }^{* *}$ Significant at 0.01 level of probability.

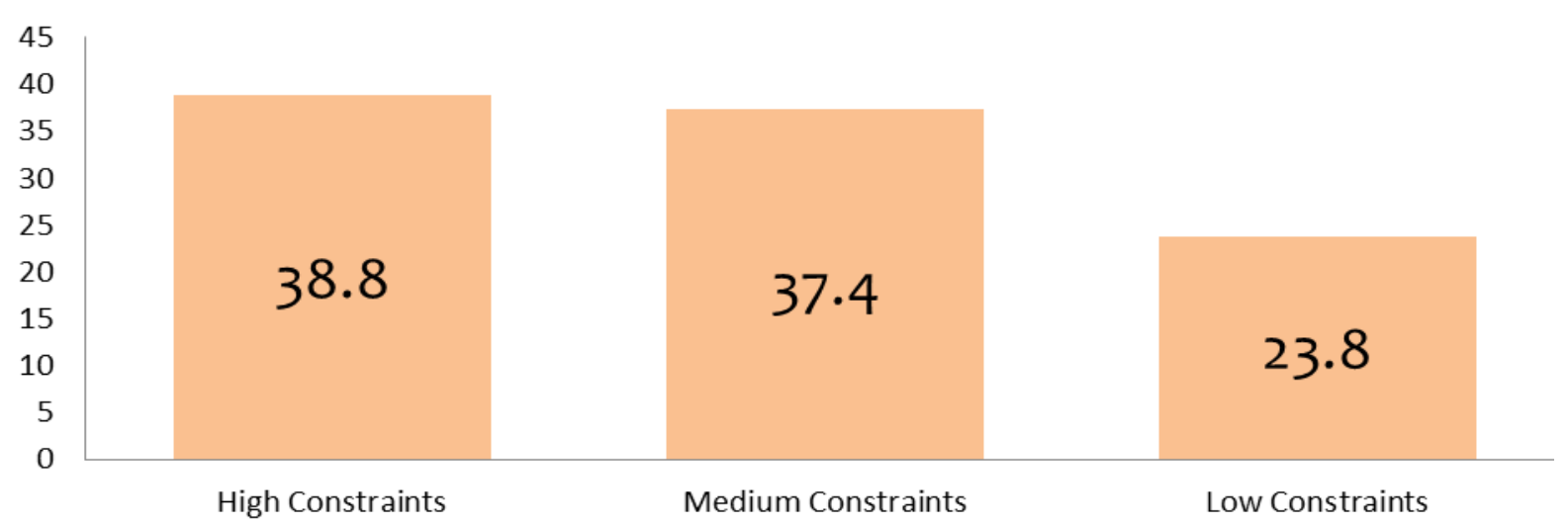

Figure 3. Overall constraints faced by the farmers in adopting farming practices.

to old aged people are not educated enough, receive less training and information from different sources and are not curious enough to the adaptation of farming practices in response to climate change, so they are facing too much constraints compare to young categories in adapting farming practices in response to climate change. The smallholder farmers are strongly facing the problem of shortage of land (96\%), lack of water $(89 \%)$, unpredicted weather $(85 \%)$, shortage of farm inputs $(80 \%)$, lack of information (73\%) and lack of credit $(62 \%)$ etc.

\section{Conclusions}

The findings of the study and the logical interpretation of their meaning in light of other relevant facts prompted the researcher to draw the following conclusion:

Average adaptation of farming practices score was found 25.74 which are not so satisfactory, because all aspects of adaptation of farming practices were not properly fulfilled by the farmers in higher extents. Thus, it can be concluded that such low to medium adaptation may not improve the livelihoods of the smallholder farmers. So, various income generating opportunities like establishment of agro-processed industry and small cottage industry should be established for increasing the smallholder farmers' income. As a result, farmers can save more money, enlarge farm size and ultimately, increase adaptation of farming practices in response to climate change. Moreover, the study revealed that education, training, communication exposure and perception of climate change of the smallholder farmers had highly positive and significant relationship with their adaptation of farming practices in response to climate change. So, proper steps should be taken by various GOs and NGOs to educate the smallholder farmers and should be involved in conducting training program to upgrade the smallholder farmers' awareness and understanding of the knowledge about climate change and its effect on agriculture and how to cope up with new climatic condition for agricultural situation. Furthermore, four variables namely level of education, perception on climate change; communication exposure and training contribute to $88.2 \%$ of the total variance in respect to the effect on adaptation of farming practices. So, in future development program regarding adaptation of different climate smart technologies in response to climate change, these variables of the farmers should take in to consideration.

Findings showed that majority of the farmers ( $76 \%)$ had faced high to moderate extent of constraints 
in adaptation of farming practices in response to climate change. So, various development agencies should motivate farming communities to adopt long-term climatic hazards mitigating measures and should provide adequate technical support, extension service in addition to education, income generating opportunity and training.

\section{Conflict of Interest}

The authors have not declared any conflict of interest.

\section{REFERENCES}

ADB (2009). The Economics of Climate Change in Southeast Asia: A Regional Review, Asian Development Bank (ADB).

Adger WN, Agrawala S, Mirza MMQ, Conde C, O'Brien K, Puhlin J, Pulwarty R, Smit B, Takahashi K (2007). Assessment of adaptation practices, options, constraints and capacity. In Climate Change 2007: Impacts, Adaptation and Vulnerability. Contribution of Working Group II to the Fourth Assessment Report of the Intergovernmental Panel on Climate Change, ed. Palutikof JP, van der Linden PJ, and Hanson CE. Cambridge: Cambridge University Press.

ASAP (2012). Adaptation for Smallholder Agriculture Program. Retrieved from: www.ifad.org. (search date: 12.12.2014).

Asian Development Bank (ADB) and International Food Policy Research Institute (IFPRI) (2009). Building climate resilience in the agriculture sector in Asia and the Pacific. Mandaluyong City, Philippines: Asian Development Bank. Available at http:// www.adb.org/ Documents/ Books/Building-ClimateResilienceAgriculture-Sector/.

Bangladesh Bureau of Statistics (BBS) (2010). Report on Bangladesh Economic Review. Dhaka: Ministry of Planning.

Bangladesh Bureau of Statistics (BBS) (2011). Labor Force Survey. Dhaka: Ministry of Planning.

BBS (2006). Community Zila Series: Satkhira, Bangladesh Bureau of Statistics. Ministry of Planning, Government of the People's Republic of Bangladesh, Dhaka.

BBS (2012). Statistical Year Book of Bangladesh. Bangladesh Bureau of Statistics. Planning Division, Ministry of Planning, Government of the People's Republic of Bangladesh, Dhaka.

Bilow t, Artner A, Siebert R, Sieber S( 2010). Micro-level Practices to Adapt to Climate Change for African Small-scale Farmers. FPRI Discussion Paper 00953, Washington, D.C.: International Food Policy Research Institute.

Boko M, Niang A, Nyong A, Vogel C, Githeko M, Mednay M, OsmanElasha B, Tabo R, Yanda P (2007). Africa. In Climate Change 2007: Impacts, Adaptation and Vulnerability. Contribution of Working Group II to the Fourth Assessment Report of the Intergovernmental Panel on Climate Change, ed. Parry ML, Canziani JP, Palutikof JP, van der Linden PJ, and Hanson CE. Cambridge: Cambridge University Press.

Boko MA, Niang A, Nyong C, Vogel M, Githeko M, Mednay B, OsmanElasha R, Tabo P, Yanda (2007). Africa. In Climate Change 2007: Impacts, Adaptation and Vulnerability. Contribution of Working Group II to the Fourth Assessment Report of the Intergovernmental Panel on Climate Change, ed. M. L. Parry, J. P. Canziani, J. P. Palutikof, P. J. van der Linden, and C. E. Hanson. Cambridge: Cambridge University Press.

Brooks N, Adger WN (2005). Assessing and enhancing adaptive capacity, In Adaptation Policy Frameworks for Climate Change: Developing Strategies, Policies and Measures, Lim B, SpangerSiegfried E, Burton I, Malone E, and Hug S (eds), Cambridge University Press, Cambridge.

CEGIS (2005). Final Report of study on Livelihood Systems Assessments, vulnerable groups profiling and livelihood adaptation to climate hazard and long term climate change in saline prone areas. Under support to the strengthening of CSMP Project. Dhaka, Bangladesh. November 2005.
Halsnaes K, Traerup S (2009). Development and climate change: a mainstreaming approach for assessing economic, social, and environmental impacts of adaptation measures. Environ. Manage. 43(5):465-778.

IPCC (2007). Summary for Policymakers. In Climate Change 2007: Impacts, Adaptati on and Vulnerability. Contributi on of Working Group II to the Fourth Assessment Report of the Intergovernmental Panel on Climate Change, Parry ML, Canziani OF, Paluti kof JP, van der Linden PJ and Hanson CE (eds), Cambridge University Press, Cambridge, United Kingdom, pp. 7-22.

Mbilinyi BP, Tumbo SD, Mahoo HF, Senkondo EM, Hatibu N (2005). Indigenous knowledge as decision support tool in rainwater harvesting. Physics and Chemistry of the Earth 30 (11-16):792-798.

NAPA (2005). Ministry of Environment and Forest, Government of the People's Republic of Bangladesh Prevention Consortium, (2007). http://www.preventionweb. Net / english / countries / statistics / ?cid $=14$ accessed on $19^{\text {th }}$ September, 2007.

Nhemachena C, Hassan R (2007). Micro-level analysis of farmers' adaptation to climate change in southern Africa. IFPRI Discussion Paper 00714. Washington, D.C.: International Food Policy Research Institute.

Osbahr H, Twyman C, Adger WN, Thomas DSG (2008). Effective livelihood adaptation to climate change disturbance: scale dimensions of practice in Mozambique. Geoforum 39(6):1951-1964.

Osman-Elasha B, Goutbi N, Spanger-Siegfried E, Dougherty W, Hanafi S, Zakieldeen S, Sanjak A, Abdel H, Elhassan HM (2006). Adaptation practices and policies to increase human resilience against climate variability and change: Lessons from the arid regions of Sudan. Working Washington, D.C.: Assessments of Impacts and Adaptations to Climate Change. P. 42.

Paavola J (2004). Livelihoods, vulnerability and adaptation to climate change in the Morogoro region, Tanzania. Working Paper EDM 0412. Norwich, U.K.: Centre for Social and Economic Research on the Global Environment, University of East Anglia.

Siedenburg J (2008). Local knowledge and natural resource management in a peasant farming community facing rapid change: $A$ critical examination. Queen Elizabeth House Working Paper Series WPS 166. Oxford: Oxford University.

Smit B, Skinner M (2002). Adaptation options in agriculture to climate change: a typology. Mitigation and Adaptation Practices and Policies for Global Change 7(1):85-114.

Thomas DSG, Twyman C, Osbahr H, Hewitson B (2007). Adaptation to climate change and variability: farmer responses to intra-seasonal precipitation trends in South Africa. Climatic Change 83(3):301-322.

Thomas TS, Mainuddin K, Chaing C (2012). Agriculture and adaptation in Bangladesh: current and project impacts of climate change. FPR Discussion Paper 00953, Washington, D.C.: International Food Policy Research Institute.

Toufiq KA (2002). Hands Not Land: How Livelihoods are changing in Rural Bangladesh. BIDS and DFID, Dhaka. September 2002.

World Bank (2006). Bangladesh Country Environmental Analysis, Bangladesh Development Series P. 12.

Ziervogel G, Catwright A, Taas A, Adejuwon J, Zermoglio F, Shale M, Smith B (2008). Climate Change and Adaptation in African Agriculture. Research Report for Rockefeller Foundation prepared by the Stockholm Environment Institute (SEI). Stockholm, Sweden. 